Roberto Cezar Datrino ${ }^{1}$

\title{
O ERP como um recurso na Empresa Brasileira de Correios e Telégrafos
}

Recebido em: 10/10/2012 - Aprovado em: 15/11/2012 - Disponibilizado em: 26/12/2012

Resumo

A proposta desse artigo é fazer uma breve reflexão sobre o ERP (Enterprise Resource Planning - Planejamento dos Recursos da Empresa) que é um modelo de gestão baseado num sistema de informação, com objetivo de promover a integração entre os processos de negócios da empresa e fornecer elementos para as decisões estratégicas. O sistema ainda possibilita à empresa automatizar e integrar a maioria de seus processos de negócio, compartilhar dados e práticas em toda a empresa e produzir e acessar as informações em tempo real. Será apresentada uma funcionalidade de informações para todas as áreas da empresa: vendas, contabilidade, engenharia, suprimentos, manufatura e também será apresentado no final um sistema ERP da Empresa Brasileira de Correios e Telégrafos e suas vantagens após a implantação.

Palavras-chave: ERP; Sistemas de informação; Empresa Brasileira de Correios e Telégrafos.

Abstract

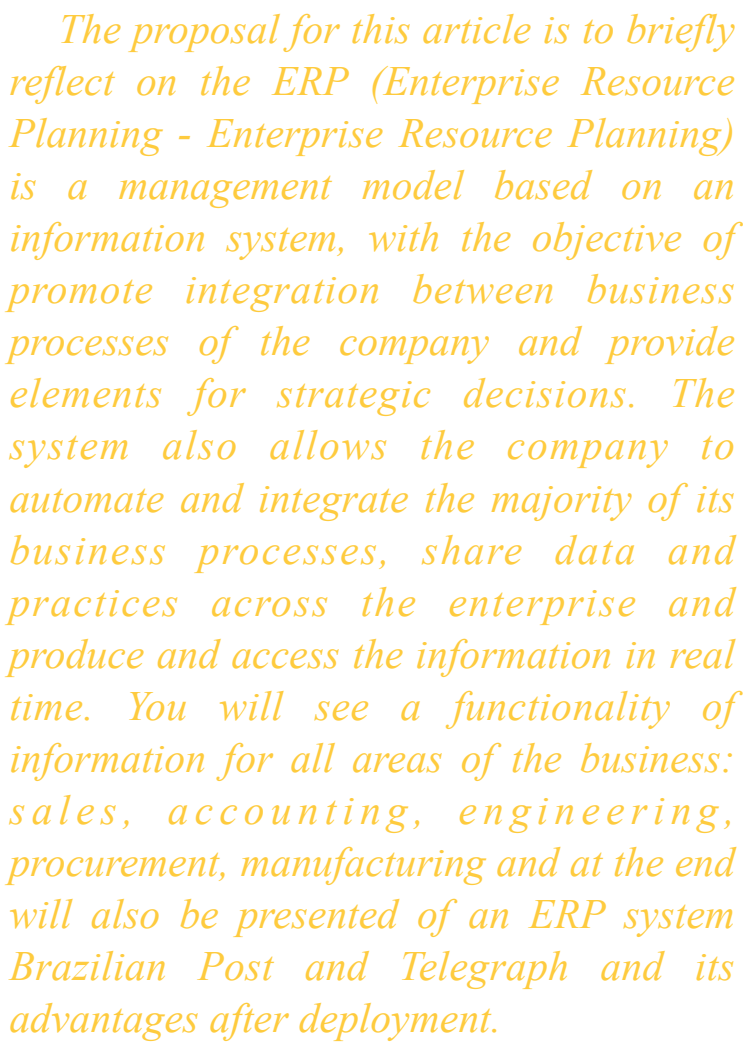

Keywords: ERP; Information Systems, Empresa Brasileira de Correios e Telégrafos.

\footnotetext{
${ }^{1}$ Roberto Cezar Datrino - Mestre em Administração de Empresas, Pós-graduado em Metodologia e Didática do Ensino Superior, Pós-Graduando em MBA Gestão de Negócios em Logística, Graduado em Administração de Empresas e Economia, Professor da Faculdade Anhanguera de Osasco e das Faculdades Campos Salles, Professor do Senac de Osasco, Membro da Equipe de Trabalhos Interdisciplinares e do Núcleo de Iniciação Científica da Faculdade Anhanguera de Osasco, Membro do Comitê Técnico-Científico do Anuário da Produção Acadêmica Docente da Revista Anhanguera Educacional, orientador dos trabalhos de conclusão de curso das Faculdades Campos Salles e das Faculdades Anhanguera de Osasco e Supervisor dos Estágios da Faculdade Anhanguera de Osasco, membro do NDE (Núcleo Docente Estruturante) dos cursos de Administração de Empresa e Logística das Faculdades Campos Salles e membro do NDE do curso de Logística da Faculdade Anhanguera de Osasco. E-mail: robertodatrino@gmail.com
} 


\section{Introdução}

Com o avanço da Tecnologia da Informação, as empresas passaram a utilizar sistemas computacionais para suportar suas atividades. Geralmente, em cada empresa, vários sistemas são desenvolvidos para atender aos requisitos específicos das diversas unidades de negócio, plantas, departamentos e escritórios. Por exemplo, o departamento de planejamento da produção utiliza um sistema próprio e o departamento de vendas utiliza outro. Dessa forma, a informação fica dividida entre diferentes sistemas.

Os principais problemas dessa fragmentação da informação são a dificuldade de obtenção de informações consolidadas e a inconsistência de dados redundantes armazenados em mais de um sistema. Os sistemas ERP (Enterprise Resource Planning - Planejamento dos Recursos da Empresa) solucionam esses problemas ao agregar, em um só sistema integrado, funcionalidades que suportam as atividades dos diversos processos de negócio das empresas.

Os sistemas ERP surgiram a partir da evolução dos sistemas MRP (Material Resource Planning). Neles, foram agregados as funções de programação mestre da produção, cálculo grosseiro de necessidades de capacidade, cálculo detalhado de necessidade de capacidade, controle do chão de fábrica, controle de compras e, mais recentemente, Sales \& Operations Planning (Planejamento de
Vendas e Operações). Dessa forma, os sistemas MRP deixaram de atender apenas às necessidades de informação referentes ao cálculo da necessidade de materiais, para atender às necessidades de informação para a tomada de decisão gerencial sobre outros recursos de manufatura. O MRP passou, então, a ser chamado de MRP II (Manufacturing Resource Planning Planejamento de Recursos de Manufatura).

Com o objetivo de ampliar a abrangência dos produtos vendidos, os fornecedores de sistemas desenvolveram mais módulos, integrados aos módulos de manufatura, mas com escopo que ultrapassa os limites da manufatura. Como exemplo, foram criados os módulos de Gerenciamento dos Recursos Humanos, Vendas e Distribuição, Finanças e Controladoria, entre outros. Esses novos sistemas, capazes de suportar as necessidades de informação para todo o empreendimento, são denominados sistemas ERP. .

\section{Alguns conceitos}

O surgimento do ERP, segundo Laugeni e Martins (2005), pode ser visto como uma evolução a partir dos sistemas MRP e MRPII. O MRP, materials requirements planining -, Planejamento das Necessidades de Materiais - surgiu em meados de 1960, a partir "da necessidade de se planejar o atendimento da demanda dependente, isto é aquela que ocorre da demanda independente". (p.354). 


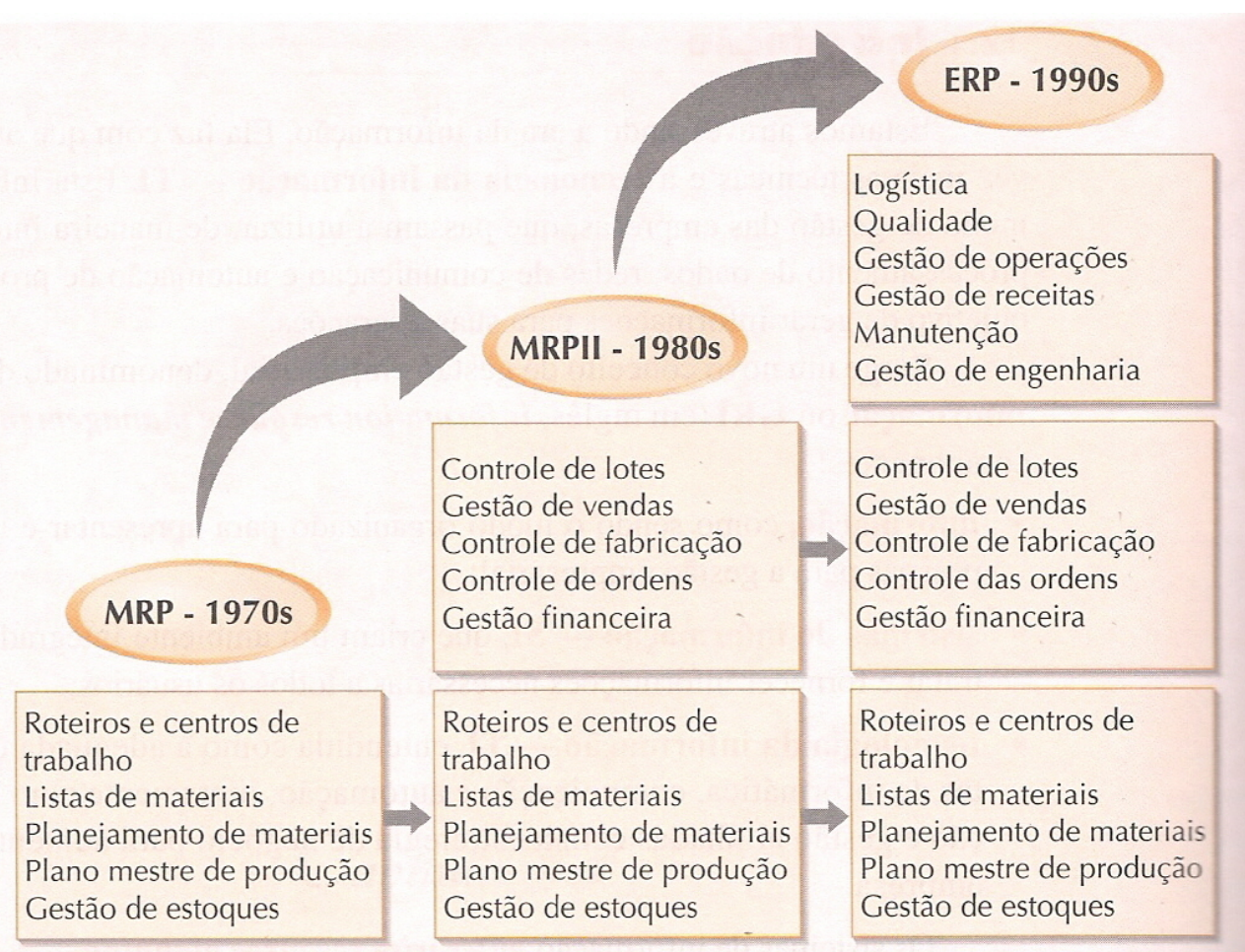

Figura 1 - Evolução dos sistemas: do MRP ao ERP. (Fonte:LAUGENI \& MARTINS, 2005, p.388).

Já no final da década de 50, quando os conceitos modernos de controle tecnológico e gestão corporativa tiveram seu início, a tecnologia vigente era baseada nos gigantescos mainframes que rodavam os primeiros sistemas de controle de estoques que tinham automatização cara e lenta, mas que já demandavam menos tempo que os processos manuais. Era necessário então, um conjunto de sistemas que possiblitasse o planejamento dos insumos internos e a comunicação e administração entre as diversas etapas de um processo produtivo.

Como grande parte das empresas produzia vários tipos de produtos, surgiu também a necessidade de um sistema de computador que pudesse auxiliar e tornar este processo mais preciso e eficaz: MRP II.

$\mathrm{Na}$ década de 80 , a tecnologia permitiu que os computadores fossem ligados em redes a servidores mais baratos e fáceis de usar que os mainframes, tornado assim, os processos logísticos mais eficientes, controlando também o maquinário envolvido nos processos. (Cf. LAUGENI \& MARTINS, 2005; GAITHER \& FRAZIER, 1999). Gera-se, então, a necessidade de integrar o MRP a outras partes da empresa, nascendo o MRPII.

O MRP II possibilita às empresas que elas aliem a lista de materiais com os pedidos em carteira dos clientes, para que sejam atendidos em tempo, além de calcular a quantidade e o momento em que haverá a necessidade de determinado material; diferenciado-se do MRP, que só conseguia determinar a lista de materiais e não conseguia tomar decisões com antecedência. 


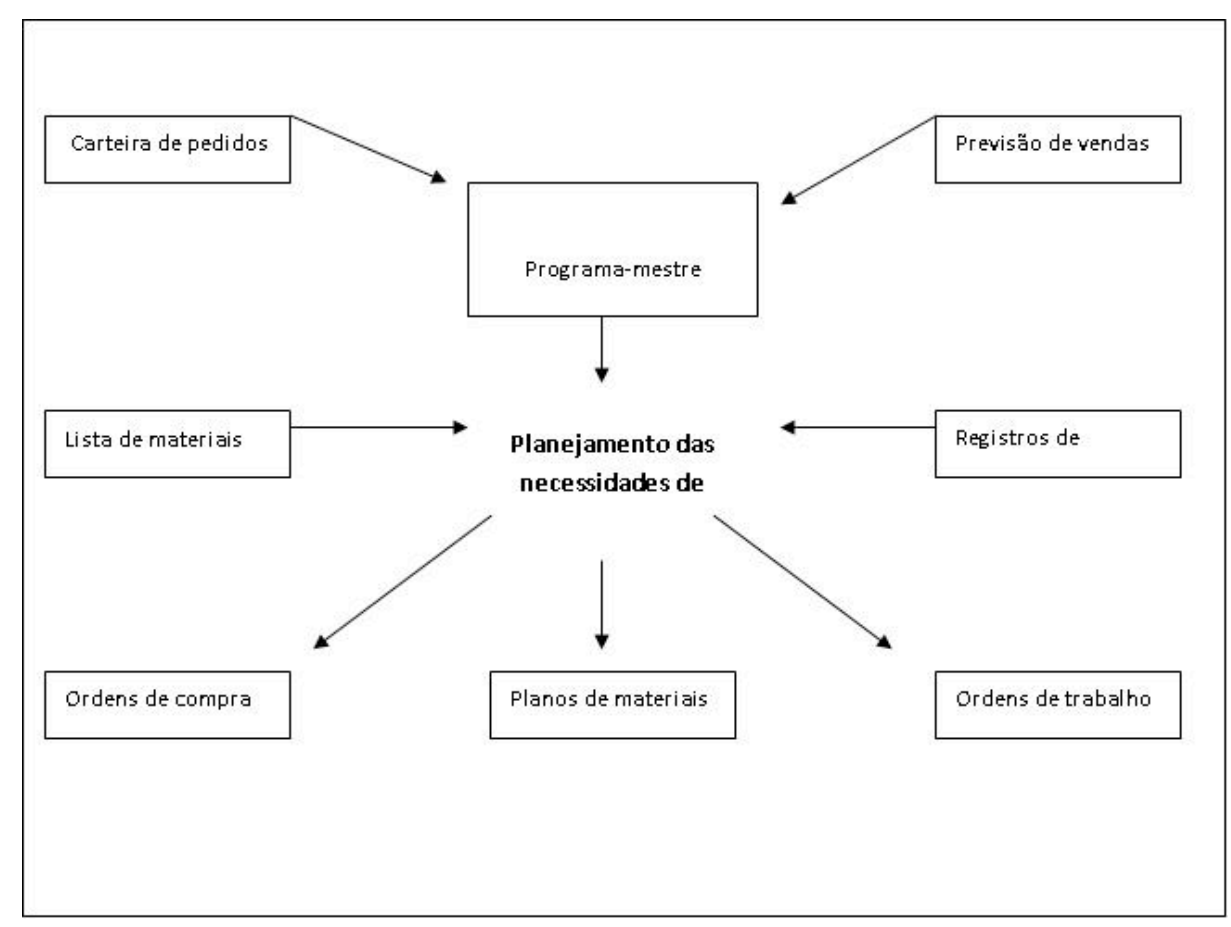

Figura 2 - Esquema de planejamento das necessidades de materiais de MRP. (Fonte: SLACK, 2002, p.455).

O MRP II apresenta-se, pois, segundo Slack et alli (2002), como uma evolução do sistema MRP e tem por finalidade dar suporte às necessidades da empresa, a partir da qual deve-se levar em consideração as decisões de capacidade, ou seja, como produzir as questões já respondidas pelo MRP. Assim esse sistema reúne os programas de controle da produção e faz uma realimentação desta informação que provém do chão de fábrica.

Assim, o novo sistema criado se baseia em uma estrutura de planejamento num processo hierárquico de decisão, verificação, visando chegar a um plano de produção viável em termos de disponibilidade de materiais e de capacidade produtiva. Portanto, o novo sistema se assemelha ao anterior na medida em que realiza a integração dos diversos setores da empresa através da informação, reduz os estoques e garante a confiabilidade na entrega, porém necessita de exatidão de dados.

Porém, o MRP II ainda depende de pessoas para ser controlado, pois são elas que farão a análise por meio dos resultados apresentados pelo sistema, para a tomada de decisão, finalizando assim o ciclo. Para Laugeni \& Martins (2005), na prática, o MRP II já poderia ser chamado de ERP pela abrangência de controles e gerenciamento.

O próximo passo seria então, já na década de 80, um sistema que pudesse agilizar os processos e que estabelecesse uma comunicação mais eficiente que os modelos anteriores. Para tal, surgiu o ERP agregado a novos sistemas de gestão. Foram diversos os departamentos que se valeram dessa nova tecnologia como: finanças, compras e vendas e recursos humanos, entre outras, ou seja, setores com uma conotação administrativa e de apoio à 
produção ingressaram na era da automação.

A nomenclatura ERP ganhou muita força, segundo Gaither e Fraizier (1999), na década de 90 , devido à revolução ocorrida com as Novas Tecnologias da
Comunicação e da Informação, que garantiam a disseminação da arquitetura cliente/servidor - microcomputadores ligados a servidores, com preços mais competitivos - e não mais mainframes.

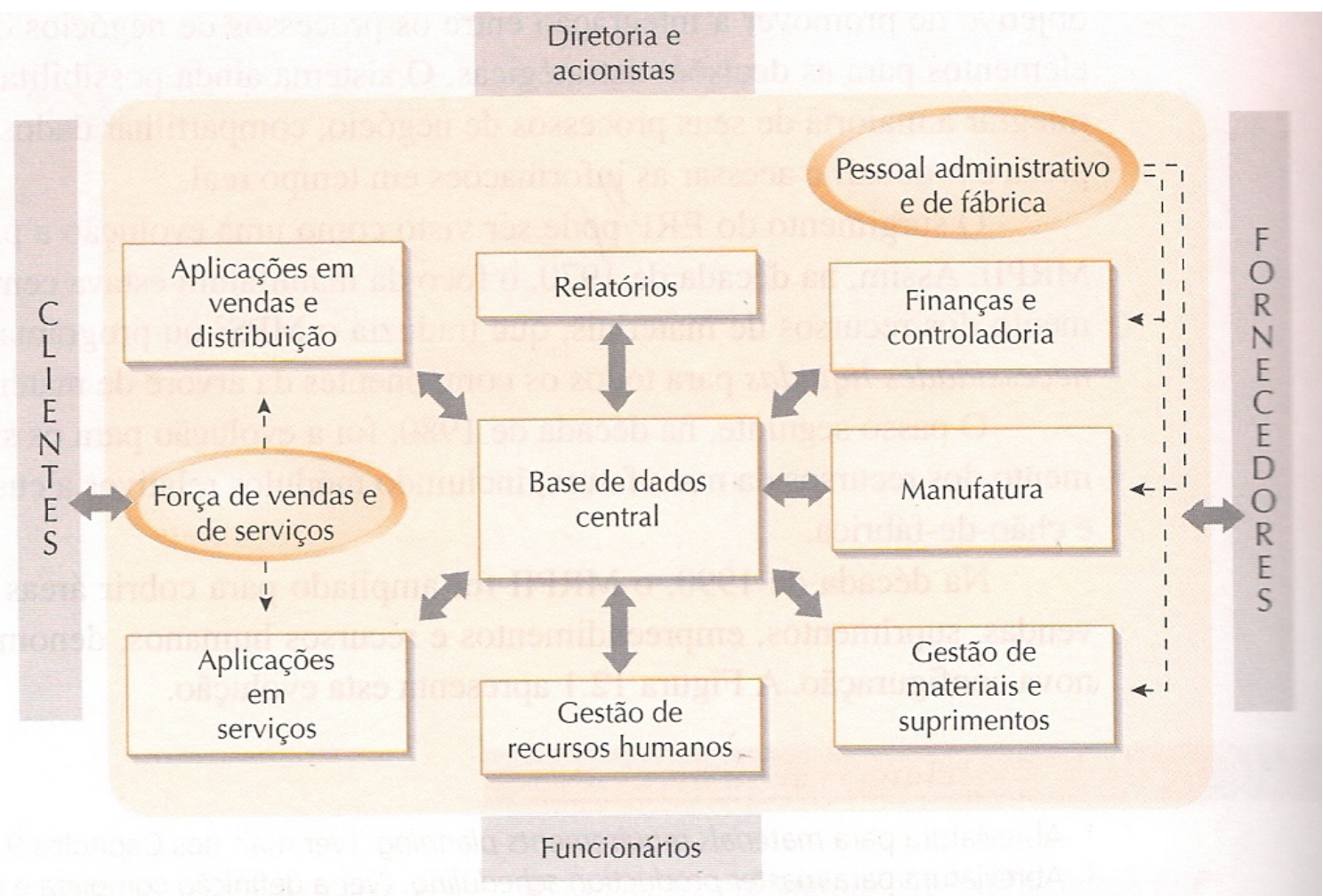

Figura 3 - visão geral de um ERP. (Fonte: LAUGENI \& MARTINS, 2005, p.388).

Assim, um sistema ERP se caracteriza por apresentar-se como suporte às necessidades de informações para a tomada de decisão gerencial de um empreendimento como um todo. Esse termo tem sido cunhado como o estágio mais avançado dos sistemas tradicionalmente chamados de MRP II. (Cf. SLACK et alli, 2002).

O ERP (Enterprise Resource Planning) ou SIGE (Sistemas Integrados de Gestão Empresarial) é um sistema da informação que integra todos os dados e processos de uma organização em um único sistema. $\mathrm{O}$ ERP, em linhas gerais, é uma plataforma de software desenvolvida para integrar os diversos departamentos de uma empresa, possibilitando a automação e armazenamento de todas as informações de negócios, eles, segundo Gaither \& Frazier (1999), automatizam processos de manufatura e modernizam departamentos corporativos. 
A integração pode ser vista sob a perspectiva funcional (sistemas de: finanças, contabilidade, recursos humanos, fabricação, marketing, vendas, compras) e sob a perspectiva sistêmica (sistema de processamento de transações, sistemas de informações gerenciais, sistemas de apoio a decisão).

O ERP é um modelo de gestão corporativo, baseado num sistema de informação, tem como objetivo promover a integração entre os processos de negócios da organização e fornecer elementos para as decisões estratégicas, isto é, é uma evolução dos modelos de sistemas apresentados anteriormente.

O sistema ainda possibilita à empresa automatizar e integrar a maioria de seus processos de negócio, compartilhar dados e práticas em toda a empresa e produzir e acessar as informações em tempo real. Os autores Laugeni \& Martins definem o ERP como:

Um software que integra todas as diferentes funções de uma empresa e que apresenta uma base de dados que opera em uma única plataforma consolidando toda a operação do negócio em um único ambiente computacional. O objetivo do ERP é de colocar a informação uma só vez no sistema, tornando-a imediatamente acessível a todos os clientes do sistema e da informação. Assim, todos utilizam sempre a mesma informação, eliminando erros. Portanto, um sistema tem características de ERP quando este possibilita à empresa automatizar e integrar a maioria de seus processos de negócio, compartilhar dados e práticas em toda a empresa e produzir e acessar as informações em tempo real. (LAUGENI \& MARTINS, 2005, p. 389).

O ERP tem como objetivos fundamentais:

- controlar e possibilitar um fluxo de informações único, contínuo e consistente por toda a empresa, o que permite administrar os negócios em uma única base de dados.

- integrar várias funções administrativas que estejam direta ou indiretamente, envolvidas com o planejamento da produção, como: controles financeiros, contabilidade, folha de pagamento, faturamento, compras, produção, estoque e logística

- fornecer suporte a todos os processos de uma empresa, sejam operacionais, produtivos, administrativos ou comerciais. (Cf. SOARES, s/d).

É um instrumento destinado à melhoria de processos e das informações em tempo real, isto é, tal sistema permite que os gestores das empresas visualizem as transações efetuadas, o impacto delas em cada área da empresa, desenhando um amplo cenário dos negócios. A implantação de um sistema ERP gera análises dos processos da empresa, treinamento dos colaboradores, investimentos em informática e reformulação nos métodos de trabalho.

O ERP atualmente está presente na maioria das empresas. Alguns autores atribuem a grande implantação desse sistema da informação, e de suas vendas, no final da década de 90, ao que foi designado na época como "bug do milênio", e também pela sua grande característica de ser um excelente sistema de controle, muito mais que de planejamento.

Para Slack et alli (2002), o sistema ERP permite que o gestor consiga analisar o que as tomadas de decisões feitas em uma parte da empresa, refletem nos demais 
departamentos. O software do ERP tem como objetivo auxiliar o gestor na tomada de decisão, ele oferece ferramentas para o desenvolvimento de novos produtos, para a compra de novos itens, inventários, integração com fornecedores e acompanhamento da produção.

O sistema opera então com uma base de dados comum, isto é, o banco de dados interage com todos os aplicativos do sistema, eliminando a redundância e redigitação de dados, assegurando a integridade e confiabilidade nas informações obtidas.
Os vendedores de ERP também oferecem aplicativos especializados em gerir processos diferenciados de atividades específicas. Tais módulos atendem a mercados verticais assim como repartições públicas, planos de saúde, financeiras, etc. A tendência atual mostra as vendas movendo-se mais ainda para áreas específicas assim como gerenciamento do chão de fábrica, logística e automação de marketing direto.

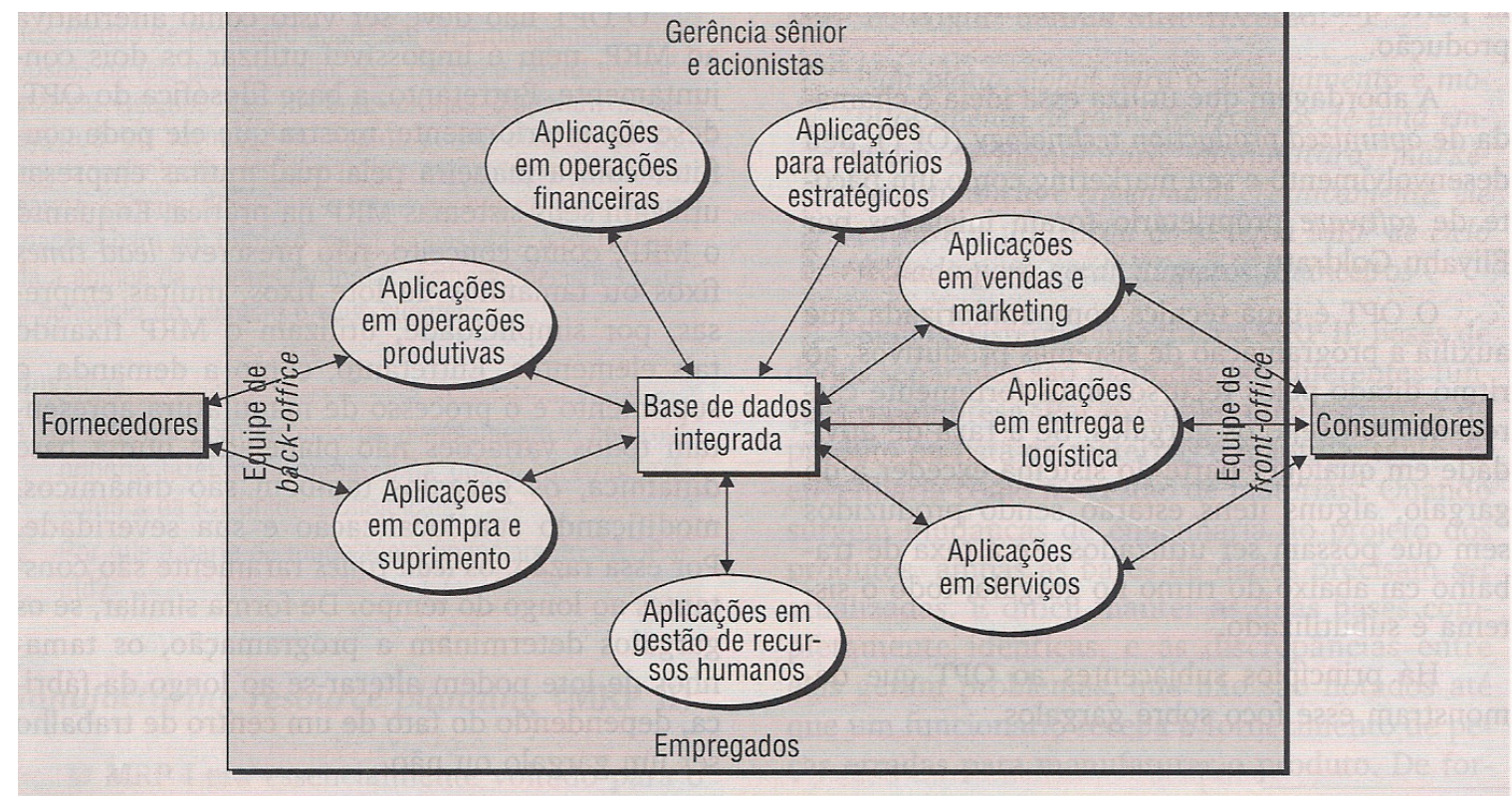

Figura 4 - A integração da informação em um sistema ERP. (Fonte: SLACK et alli, 2002, p.474).

\section{A importância do ERP nas empresas}

Entre as mudanças mais palpáveis que um sistema de ERP propicia a uma corporação, sem dúvida, está a maior confiabilidade dos dados, agora monitorados em tempo real, e a diminuição do retrabalho. Algo que é conseguido com o auxílio e o comprometimento dos funcionários, responsáveis por fazer a atualização sistemática dos dados que alimentam toda a cadeia de módulos do ERP e que, em última instância, fazem com que a empresa possa interagir.

Assim, as informações trafegam pelos módulos em tempo real, ou seja, uma ordem de vendas dispara o processo de 
fabricação com o envio da informação para múltiplas bases, do estoque de insumos à logística do produto. Tudo realizado com dados orgânicos, integrados e não redundantes.

Para entender melhor como isto funciona, o ERP pode ser visto como um grande banco de dados com informações que interagem e se realimentam. Assim, o dado inicial sofre uma mutação de acordo com seu status, como a ordem de vendas que se transforma no produto final alocado no estoque da companhia.

O ERP automatiza as tarefas envolvendo a performance de um processo, tal qual a finalização de um pedido, o qual envolve pegar o pedido de um cliente, enviá-lo e cobrá-lo. Com o ERP, quando um representante recebe o pedido de um cliente, o sistema apresenta as informações necessárias para completálo.

Todas as pessoas na empresa vêm o mesmo visor e têm acesso a um único banco de dados que guarda o novo pedido do cliente, fazendo com que não haja, ou se diminua, o retrabalho, os ruídos e a perda de tempo em repassar as informações. Quando um departamento termina a sua parte em um pedido, este é enviado automaticamente para o próximo departamento através do ERP. Para saber em que ponto está um pedido, em um determinado momento, é só verificar no sistema.

Ao desfazer a complexidade do acompanhamento de todo o processo de produção, venda e faturamento, a empresa tem mais subsídios para se planejar, diminuir gastos e repensar a cadeia de produção.
Um bom exemplo de como o ERP revoluciona uma companhia é que com uma melhor administração da produção, um investimento, como uma nova infraestrutura logística, pode ser repensado ou simplesmente abandonado. Neste caso, ao controlar e entender melhor todas as etapas que levam a um produto final, a companhia pode chegar ao ponto de produzir de forma mais inteligente, rápida e melhor, o que, em outras palavras, reduz o tempo que o produto fica parado no estoque.

A tomada de decisões também ganha outra dinâmica. Imagine uma empresa que por alguma razão, talvez uma mudança nas normas de segurança, precise modificar aspectos da fabricação de um de seus produtos.

Com o ERP, todas as áreas corporativas são informadas e se preparam de forma integrada para o evento, das compras à produção, passando pelo almoxarifado e chegando até mesmo à área de marketing, que pode assim ter informações para mudar algo nas campanhas publicitárias de seus produtos, e ser realizado em muito menos tempo do que seria possível sem a presença do sistema.

Entre os avanços palpáveis, podemos citar o caso de uma indústria média norteamericana de autopeças, situada no estado de Illinois, que conseguiu reduzir o tempo entre o pedido e a entrega de seis para duas semanas, aumentando a eficiência na data prometida para envio do produto de $60 \%$ para $95 \%$ e reduzindo as reservas de insumos em $60 \%$. Outra diferença notável: a troca de documentos entre departamentos que demorava horas ou mesmo dias caiu para minutos e até segundos.

Esse é apenas um exemplo. Porém, de acordo com a empresa, é possível 
direcionar ou adaptar o ERP para outros objetivos, estabelecendo prioridades que podem tanto estar na cadeia de produção quanto no apoio ao departamento de vendas como na distribuição, entre outras.

Com a capacidade de integração dos módulos, é possível diagnosticar as áreas mais e menos eficientes e focar em processos que possam ter o desempenho melhorado com a ajuda do conjunto de sistemas.

Para Laugeni \& Martins,

o ERP é um sistema que facilita o fluxo de informações dentro de uma empresa, integrando as diferentes funções: manufatura, logística, finanças, recursos humanos e engenharia, entre outras. Ainda apresenta uma base de dados que opera em uma única plataforma e que consolida todas as informações em um único ambiente computacional. (LAUGENI \& MARTINS, 2005, p. 388).

Há várias razões pelas quais as empresas implementam o sistema ERP, a saber, alumas delas: permanecer competitivas no mercado; melhorar a produtividade, a qualidade e os serviços prestados aos clientes, uma vez que estará unificando processos, métodos e sistemas dentro de diferentes unidades da empresa; reduzir custos dos estoques e sua respectiva alocação; para integrar dados financeiros, fazendo com que haja uma unificação, por exemplo, de valores entre os diversos departamentos de uma empresa; para uniformizar as informações de Recursos Humanos, fazendo com que o funcionário receba de forma mais eficiente, eficaz e em menor tempo, informações sobre benefícios e serviços.

Alguns fornecedores de sistemas ERPs são: SAP (Alemã), Oracle (USA), (Brasileiros), Microsiga, Datasul, Starsoft e Siscorp.

\subsection{Vantagens do ERP}

Para Laugeni \& Martins: (Laugeni e Martins, 2005, p. 389) a vantagem do ERP é que ele possibilita o acesso mais fácil às informações pelo fato de ser um sistema integrado. $\mathrm{O}$ sistema integrado permite melhorar as informações gerenciais e assegura dados consistentes e maneiras de cálculo idênticas para as mesmas medidas em cada um dos negócios da empresa.

Um dos pontos fortes do sistema, conforme afirma Laudon (2004), é a integração entre os módulos. Os monitores, as operações e a navegação dentro do sistema são de tal forma padronizada que, à medida que o utilizador se familiariza com um módulo, aprende mais facilmente e rapidamente os demais. Os acessos às informações são realizados através de menus com utilização de senhas, permitindo que se controle quais os utilizadores que têm acesso a que tipo de informações. Além disso, os menus são customizados de forma que cada utilizador visualize e tenha acesso somente às operações que atendam aos objetivos específicos de seu interesse.

Algumas das vantagens da implementação de um ERP numa empresa são, conforme Slack (2002):

- eliminar o uso de interfaces manuais;

- reduzir custos;

- otimizar o fluxo da informação e a qualidade da mesma dentro da organização (eficiência);

- otimizar o processo de tomada de decisão;

- eliminar a redundância de atividades; 
- reduzir os limites de tempo de resposta ao mercado;

- reduzir as incertezas do Lead time;

- incorporar melhores práticas (codificadas no ERP) aos processos internos da empresa;

- auxiliar na formação dos custos.

O sistema serve como instrumento de planejamento, pois permite à empresa calcular o planejamento de compras, a necessidade de contratação ou demissão de pessoal, quanto a empresa necessita de capital de giro, necessidade de equipamentos e demais insumos produtivos.

Serve também como um simulador, permitindo que empresa visualize diferentes cenários nos quais possa vir a atuar, considerando as diferentes demandas e seus efeitos. É um excelente instrumento para tomada de decisão.

As soluções ERP ajudam a ganhar eficiência e a diminuir custos. As reduções de custos obtêm-se pela eficiência nas funções administrativas, pelo controle de estoques e pelas melhorias nos níveis dos serviços e ciclos produtivos. As soluções de ERP dão suporte aos principais processos e funções da empresa, integrando os dados procedentes de diferentes áreas.

As vantagens que justificam a implantação de uma solução ERP são, segundo Laudon (2004), muito semelhantes às apresentadas pelo autor citado anteriormente, a saber:

- um sistema totalmente integrado;
- melhor comunicação não só interna, mas também externa;

- maior eficiência e níveis de produtividade;

- eliminar a redundância de atividades;

- melhorar a monitoração e facilitar o processo de planejamento empresarial;

- melhorar o serviço prestado ao cliente;

- eliminar o uso de interfaces manuais;

- garantir a disponibilidade da informação de suporte à tomada de decisão contribuindo para a sua otimização;

- delegar as decisões nos níveis convenientes, mantendo o controle de gestão adequado.

\subsection{Desvantagens do ERP}

Geralmente, as desvantagens na implementação de um sistema ERP são menores que as vantagens, sendo que muitas das dificuldades encontradas podem ser evitadas caso sejam realizados investimentos, formação e envolvimento adequados.

O sistema é uma ferramenta para auxiliar o controle e planejamento dos processos de compra de matéria-prima e de produção, porém ele depende muito do comprometimento de seus operadores para que ele seja funcional.

No entanto, o sucesso da implantação deste sistema não depende só da experiência e das competências da força de trabalho para se adaptar rapidamente ao novo, mas sim de outras situações, como: 
(Cf. LAUGENI \& MARTINS, 2005; LAUDON, 2004).

- A customização em muitas situações é limitada e dispendiosa;

- requer mudanças substanciais na organização e nos seus processos (reengenharia);

- processo de implementação é longo e complexo;

- os sistemas ERP podem ter custo proibitivo para instalar e executar;

- a utilização do ERP por si só não torna uma empresa verdadeiramente integrada;

- dependência perante o fornecedor do ERP;

- torna os módulos dependentes uns dos outros, pois cada departamento depende das informações do módulo anterior. Logo, as informações têm que ser constantemente actualizadas, uma vez que as informações são em tempo real (on line), ocasionando maior trabalho;

- excesso de controle sobre as pessoas, o que aumenta a resistência à mudança e pode gerar desmotivação nos funcionários.

Os principais fatores críticos de sucesso para um projeto de implantação de um ERP podem ocorrer devido à falta de envolvimento do usuário e ao apoio da direção, à falta de um planejamento adequado e de marcos intermediários; comprometimento; visão e objetivos claros; infra-estrutura adequada.
3.3. Módullos hoje disponíveis na Maioria dos ERPs

Hoje, embora com diferenças de nomenclaturas, os ERPs mais avançados possuem módulos integrados (o que significa integração e qual o grau de integração são perguntas pertinentes) que abrangem o seguinte escopo:

a) Módulos relacionados a Operações e Supply Chain Management: Previsões / Análises de Vendas (forecasting / Sales analysis); Listas de Materiais (BOM Bills of Material); Programação Mestre de Produção / Capacidade Aproximada (MPS - Master Production Schedulling/RCCP Rough-CUT Capacity Planning); Planejamento de Materiais (MRP Material Requirements Planning); Planejamento Detalhado de Capacidade (CRP - Capacity Requirements Planning); Compras (Purchasing); Controle de Fabricação (SFC - Shop Floor Control); Controle de Estoques (Inventory); Engenharia (Engineering); Distribuição Física (DRP - Distribution Requirements Planning); Gerenciamento de Transporte (TM - Transport Management); Gerenciamento de Projetos (Project); Apoio à Produção Repetitiva; Apoio à Gestão de Produção em Processos; Apoio à Programação com Capacidade Finita de Produção Discreta; Configuração de Produtos.

b) Módulos relacionados à Gestão Financeira / Contábil / Fiscal: Contabilidade Geral; Custos; Contas a Pagar; Contas a Receber; Faturamento; Recebimento Fiscal; Contabilidade Fiscal; Gestão de Caixa; Gestão de Ativos; Gestão de Pedidos; Definição e Gestão dos Processos de negócio (Workflow). 
c) Módulos relacionados à Gestão de Recursos Humanos: Pessoal (Personell) e Folha de Pagamentos (Payroll).

\section{O ERP na Empresa de Correios e Telégrafos}

A ECT deu um passo importante na implementação da Solução Integrada de Gestão Empresarial (ERP). Após adotá-la nas áreas de recursos humanos (cadastro, benefícios e pagamentos) e financeira (contabilidade, cadastro de órgãos e fluxo de caixa), chegou a vez da área de administração, com a implantação do módulo de Ativo Fixo (bens móveis) e do módulo de gestão de contratos nas DRs Diretorias Regionais e na AC Administração Central. Tratou-se de um trabalho complexo, uma vez que envolveu o exame e o "carregamento" no sistema de dados relativos a mais de 8.200 contratos da ECT com fornecedores. Na área de administração, a implantação do ERP alcançou os módulos de contratações, licitações e estoque.

Foi implantado o módulo de manutenção da área de tecnologia pela manutenção corretiva, foram concluídas as funcionalidades de manutenção preventiva e a utilização de coletores de dados portáteis para abertura de ordem de serviço.

Instalar o ERP é um processo que demanda tempo nas empresas, uma vez que sua implantação, em média, é de três a seis meses e as transformações ocorrem efetivamente entre um e três anos; porém, mesmo assim, sua utilização é de grande valia para as empresas, já que se configura como um projeto com retorno de capital financeiro garantido, podendo gerar uma economia anual em torno de U\$1.6 milhões. (PADOVOZE, 2004).

A implantação desse sistema integrado de informações requer uma reorganização na forma como as atividades estão estruturadas, além de externamente com clientes, fornecedores ou parceiros, mas, sobretudo, internamente na empresa.

$O$ ERP foi integrado à infraestrutura de gestão da ECT pela automatização dos processos, agilizando o fluxo de informações sobre processos administrativos e de negócios. Por meio do ERP, dados são compartilhados de forma rápida pelas áreas da empresa. "Os benefícios do ERP são muito grandes", diz o gerente da Diretoria de Tecnologia da ECT. "Onde a solução foi implantada, melhorou todos os processos internos."

A transformação dos dados gerados pelo ERP em informações é viabilizada pelo Data Warehouse, que funciona como um armazém de dados, permitindo o cruzamento de informações históricas de diversas áreas e municiando a administração de informações na tomada de decisões. "Ele armazena o passado, auxiliando na realização de projeções, análises e simulações", diz o gerente da Diretoria de Tecnologia da ECT.

$\mathrm{Na}$ área de recursos humanos, é possível analisar pagamentos, cadastro, benefícios e cargos e salários sob vários ângulos, como visões do efetivo por unidade, tipo de despesa ou de benefício. A solução permite análise do perfil dos empregados por faixa etária, sexo, nacionalidade, escolaridade e tipo de dependente.

$\mathrm{Na}$ área financeira, analisa a evolução dos saldos de conta contábil. $\mathrm{Na}$ área operacional, é possível estabelecer visões gerenciais sobre o tratamento e a 
distribuição de encomendas e cartas registradas, de modo a avaliar o tempo médio entre postagem e entrega, taxa de ocupação das aeronaves e tipos de objetos transportados. $\mathrm{Na}$ área comercial, os executivos podem analisar os produtos mais vendidos e sua sazonalidade por região ou agência.

A implantação do ERP confirma a estratégia da ECT de se manter alinhada com as mais avançadas tendências de gestão empresarial. Exemplo é a comercialização de selos. No sistema tradicional, as operações de venda devem ser informadas várias vezes a diferentes áreas da empresa, de modo a assegurar fluxo constante de impressão, remessa e a manutenção de níveis adequados de estoque. Com o ERP, a venda é informada uma vez. Em tempo real, os dados são enviados às áreas envolvidas. Integrados num único sistema, ficam disponíveis aos setores que deles necessitam. Com isso, os processos e o controle administrativo ficam mais eficazes.

A Empresa de Correios e Telégrafos realizou a implantação da Solução Integrada de Gestão Empresarial (ERP), e teve todos os seus módulos completamente implantados na ECT, ação que representou a consolidação de mais uma etapa do esforço de modernização tecnológica do dia-a-dia da empresa, ganhando em eficiência. A adoção do ERP teve como finalidade promover a integração da infraestrutura de gestão da empresa por meio da automatização de processos.

O novo sistema tornou mais ágil todo o fluxo de informações corporativas, com impactos positivos em toda a organização, principalmente nas áreas administrativas e de negócios, graças à padronização de procedimentos e ao estabelecimento de uma base única de dados para onde convergem às informações corporativas. Ao possibilitar uma gestão mais eficiente, o ERP favorece a aplicação de práticas mais eficazes no desenvolvimento dos processos administrativos e dos negócios, com ganhos de produtividade e velocidade na tomada de decisões.

Com a solução implantada, os dados gerados pela ECT poderão ser compartilhados de forma rápida pelas mais diversas áreas da organização. Outra vantagem da integração do fluxo de dados corporativos é a conquista pelo empregado de uma maior objetividade no exercício das atividades profissionais, o que contribui para a eliminação de trabalhos repetitivos e redundantes.

"Com os recursos do ERP, o colaborador passa a ser um profissional ainda mais pró-ativo", diz o gerente da Diretoria de Tecnologia e Infra-estrutura. "O profissional terá mais tempo para dedicar-se às atividades de análise e de planejamento, graças à interatividade proporcionada pela solução."

O ERP já faz parte da rotina dos colaboradores das áreas econômicofinanceira, comercial, de recursos humanos, administração e tecnologia da empresa nos módulos de Contabilidade, Orçamento e Contas a Pagar, Força de Vendas, Folha de Pagamentos, Cadastro e Benefícios, Gestão de Contratos, Contratações e Controle de Estoques e Manutenção de Equipamentos. O módulo operacional foi implantado na DR-PR (Diretoria Regional do Paraná) para validação dos procedimentos, abrangendo o controle da frota de veículos. Todos os 
recursos da solução tecnológica foram integrados a esse segmento da ECT.

As áreas da Empresa de Correios e Telégrafos apresentam como módulos de ERP implantados: a) Área Administrativa: Módulo Contabilidade; Módulo Tributos; Módulo Contas a Pagar; Módulo Faturamento; Módulo Contas a Receber; Módulo Custos; Módulo Orçamento; Módulo de Cadastro; Módulo de Tabela Corporativa de Órgãos - TCO; b) Área Comercial: Módulo Gestão de Contratos; Módulo Contratação; Módulo Ativo Fixo (Patrimônio); Módulo Estoque e Distribuição; Módulo de Manutenção de Equipamentos; Módulo de Estoques; Módulo Operacional - Gestão de Frotas; Módulo Operacional - Gestão de Linhas Transportes de Cargas Postal.

\section{Considerações Finais}

Podemos considerar nesse artigo que cremos que a implantação e uso do sistema ERP exige que a empresa se reorganize, tendo como foco o processo do seu negócio como um todo, eliminando a gestão departamentalizada da empresa. Isso é facilitado pelo sistema ERP, pois este é integrado, e as informações que são geradas por um departamento são compartilhadas por outros.

O ERP facilita o controle, pois com todas as informações armazenadas no sistema, pode-se verificar o desempenho das várias áreas da empresa. Também fornece suporte as tomadas de decisões da média e alta gerência. Como poderá verificar na Empresa Brasileira de Correios e Telégrafos.
A implantação do sistema ERP na Empresa de Correios e Telégrafos, utilizado como exemplo prático nesse estudo, proporcionou um melhor controle, um atendimento mais eficaz e maior qualidade dos serviços. O novo sistema torna mais ágil todo fluxo de informações corporativas, com impactos positivos em toda a organização, principalmente nas áreas administrativas e de negócios, graças à padronização de procedimentos e ao estabelecimento de uma base única de dados para onde convergem as informações corporativas.

Ao possibilitar uma gestão mais eficiente, o ERP favorece a aplicação de práticas mais eficazes no desenvolvimento dos processos administrativos e dos negócios, com ganhos de produtividade e velocidade na tomada de decisões.

O sistema de automação da rede de agências possibilitou um melhor gerenciamento das atividades comerciais, financeiras e tecnológicas. O sistema ERP tornou mais ágil, todo o fluxo de informações corporativas com impactos positivos em toda empresa, levando a decisões estratégicas mais precisas e mais rápidas.

Este artigo com o tema "ERP (Enterprise Resource Planning Planejamento dos Recursos da Empresa)" pretende resumir as características desse sistema e apresentar as suas contribuições para as empresas. Não pretende esgotar o assunto, apenas fornecer a base para um melhor entendimento sobre o que se espera de uma grande empresa que utiliza este sistema e incentivar novas pesquisas nessa área. 


\section{Referências Bibliográfícas}

CORRÊA, H. L. Planejamento, Programação e Controle da Produção: MRP II/ERP conceitos, uso e implantação. São Paulo. Atlas. 2001.

EMPRESA DE CORREIOS E TELÉGRAFOS. Disponível em: <www.correios.com.br>. Acesso em 13 mai. 2010.

GAITHER, N. \& FRAZIER, G. Administração da Produção e operações. São Paulo: Guazzelli, 1999.

LAUDON, K. C. Sistemas de Informações gerenciais: administrando a empresa digital. São Paulo: Prentice Hall. 2004.

LAUGENI, F.P. \& MARTINS, P.G. Administração da Produção. São Paulo: Saraiva, 2005. PADOVOZE, C. L. Sistemas de informações contábeis: fundamentos e análise. São Paulo: Atlas. 2004.

P R E . Disponíve 1 e m: <ht t p://groups.google.com.br/group/ publicitariosversuspublicidadepropaganda/browse_thread/thread/e36970308b5daeab $>$. Acesso em 10 mai. 2010.

SLACK, N. et alli. Administração da produção. São Paulo: Atlas, 2002.

SOARES, E. “O que é um sistema ERP”. Disponível em:

$<\mathrm{http}$ ://wnews.uol.com.br/site/noticias/materia_especial.php? id_secao=17\&id_conteudo=452>. Acesso em 10 mai. 2010. 